\title{
Isolation and Characterization of a cDNA for Chalcone Synthase from Cultured Cells of the Strawberry Fragaria ananassa, cv Shikinari
}

\author{
Miei SAKURAI*, Yoshihiro OZEKI** and Tsukasa MORI***
}

Received 20 January 1997; accepted 12 June 1997

CHS (chalcone synthase, EC 2.3.1.74) is the first step enzyme involved in the flavonoid biosynthetic pathway. CHS cDNA was first obtained from cultured parsley cells [1], subsequently cDNAs of CHS have been obtained from various plant species. Furthermore, the mechanism of CHS gene expression regulated by cis-elements and transacting factors has been thoroughly examined in response to stresses, such as ultraviolet illumination [2] and elicitor [3].

Synthesized anthocyanin in strawberry fruit, has allowed the identification of the primary pigment, pelargonidin-3-glucoside $(88 \%)$, and the secondary pigment, cyanidin-3-glucoside (12 \%) [4]. It has been reported that the mechanism of ripening for strawberry fruit is not related to increased ethylene but a decline in the production of auxin in the achenes as the fruit matures [5].

We prepared a suspension culture of $F$. ananassa, cv Shikinari. The suspension-cultured cells were subcultured under the condition of darkness without anthocyanin accumulation. When the cells were illuminated, large quantities of anthocyanin rapidly accumulated [6]. In contrast with strawberry fruit ripening, auxin did not affect the anthocyanin accumulation in the suspension-cultured cells [7]. Furthermore, the anthocyanin components in cultured cells are different from those in strawberry fruit. The primary anthocyanin accumulated in cultured cells was peonidin-3-glucoside and the secondary pigment was cyanidine-3-glucoside [6].

The discrepancy between fruit and suspension-cultured cells suggests that the regulatory mechanisms for the expression of enzymes involved in anthocyanin biosynthetic pathway might be different under differentiated (e.g., fruit ripening) and undifferentiated (e.g., suspension-cultured cells) states. Recently, a partial CHS cDNA was identified in the ripening fruit of $F$. ananassa, cv Pajaro, using polymerase chain reaction differential display [8]. The first step in studying the regulatory mechanisms of anthocyanin biosynthesis in $F$. ananassa should be

* Environmental Process Development Department, Research Institute, Ishikawajima Harima Heavy Industries, Co., Ltd., I Shinnakahara, Isogo-ku, Yokohama 235, Japan

** Department of Biotechnology, Tokyo University of Agriculture and Technology, Koganei, Tokyo 184, Japan

*** Faculty of Fisheries, Hokkaido University, 3-1-1 Minato, Hakodate 041, Japan to obtain full-length CHS cDNA and examine the expression pattern during anthocyanin synthesis.

Suspended cell cultures of the strawberry $F$. ananassa, cv Shikinari, were established in 1993 [6] and subcultured in $100 \mathrm{~m} l$ of liquid Linsmaier and Skoog (LS) [9] medium supplemented with $3 \%$ sucrose, $2,4-\mathrm{D}(1 \mathrm{mg} / l)$ and BA $(0.1 \mathrm{mg} / l)$ in $500 \mathrm{~m} l$ flasks. Cells were incubated on a gyratory shaker (80 rpm) under 800 lux (white fluorescent light: FL40SSW/37, Toshiba) at $25^{\circ} \mathrm{C}[6]$. The cells were subcultured every week. Under these conditions, little anthocyanin accumulated. To induce anthocyanin production, seven-day-old subcultured cells (2 $\mathrm{g}$ of fresh weight) were transferred to fresh LS medium and cultured in darkness for four days, and thereafter cultured under 8,000 lux to produce anthocyanin. Cells were harvested at $0,6,12,24,36,48,60,72,84$ and $102 \mathrm{hr}$ after light illumination (8,000 lux).

For the preparation of cDNA libraries, total mRNA was extracted from $100 \mathrm{~g}$ fresh weight of cultured strawberry cells accumulating anthocyanin in an LS medium under 8, 000 lux for one week using the SDSphenol method. Total RNA was dissolved in TEHPRI (10 mM Tris-HCl, pH 7. 5, 1 mM EDTA, 1 mM dithiothreitol, and five units $\mathrm{m} l^{-1}$ ribonuclease inhibitor from human placenta) and layered on a 5. $7 \mathrm{M}$ $\mathrm{CsCl}$ cushion and precipitated by centrifugation at $110,000 \times \mathrm{g}$ for $20 \mathrm{hr}$. Poly (A) + RNA was isolated from total RNA using oligo-d(T) latex (Roche, Tokyo) as described in the manual from the supplier. A cDNA library was constructed in $\lambda$ gt22A using the Super Script Lambda System for cDNA synthesis and cloning (BRL). The phage clones containing cDNAs for CHS mRNA were screened using a CHS cDNA probe derived from carrot [10]. A cDNA insert was digested separately with restriction enzymes, NotI and SalI. The resulting DNA fragments were ligated into pSPORT I and transferred to competent cells (E. coli JM109). The DNA sequences were determined using an automated DNA sequencer (Applied Biosystems).

Total RNA was extracted from $2 \mathrm{~g}$ fresh weight of cells and fractionated by electrophoresis in a $1.2 \%$ formaldehyde-agarose gel, and then blotted onto a nylon membrane (HybondN ${ }^{+}$, Amersham Japan). Hybridization was performed overnight at $65^{\circ} \mathrm{C}$ in $5 \times$ 


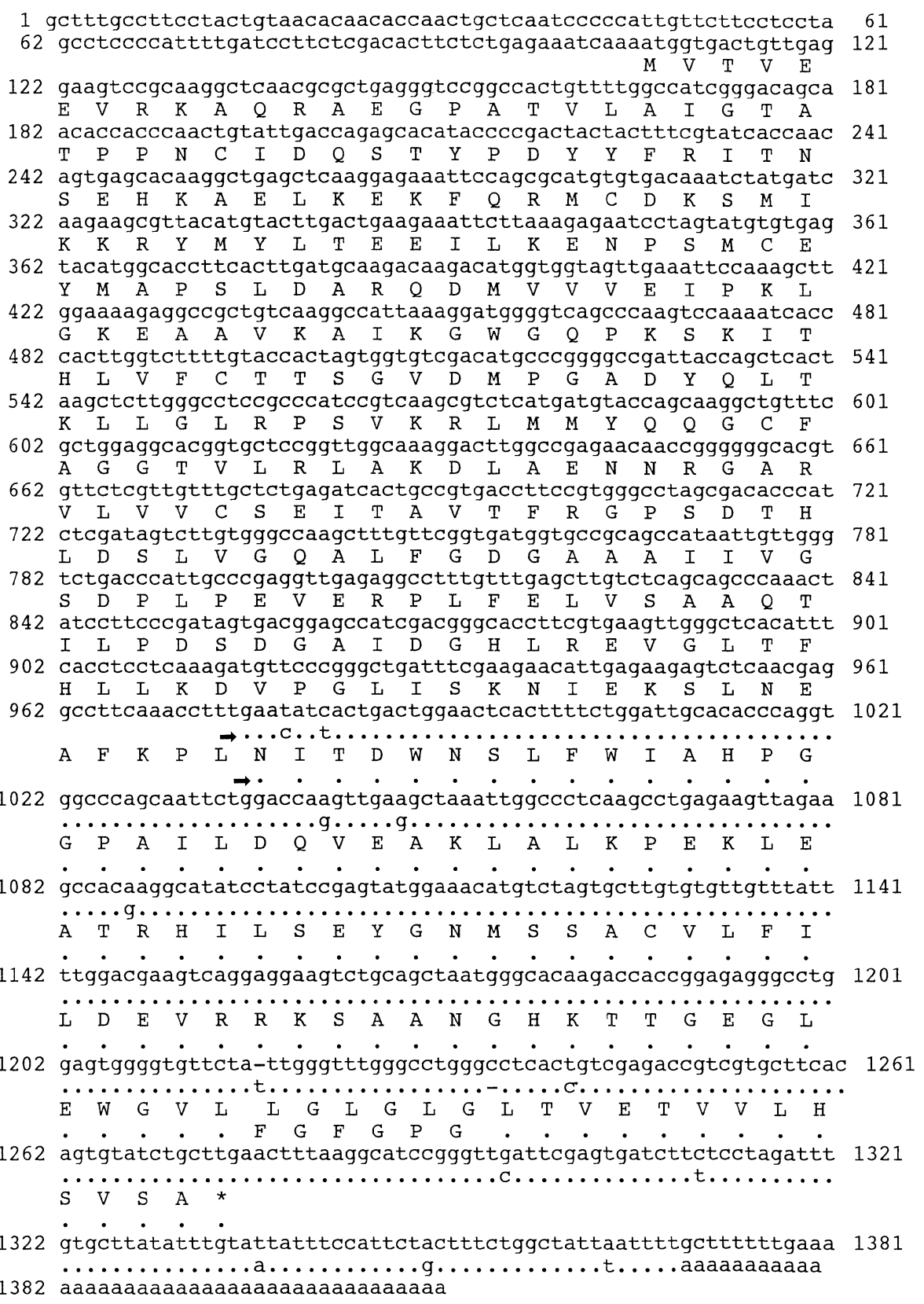

Fig. 1 The nucleotide and deduced amino acid sequences of CHS cDNA obtained from cultured strawberry cells.

The nucleotide and deduced amino acid sequences of CHS cDNA from cultured strawberry cells are shown by small letters and capital letters, respectively. Nucleotide and deduced amino acid sequences of a partial fragment of CHS cDNA from strawberry fruit reported by Wilkinson et al. (DDBJ/EMBL/Gen-Bank Database under the accession number U19942) are shown on the lane started by arrows. Same nucleotides and amino acids are shown by dots. The sequence data will appear in the DDBJ/EMBL/Gen-Bank Databases under the accession number AB003394.

SSC, $10 \times$ Denhard's solution, $10 \mathrm{mM}$ of sodium phosphate (pH 6.5), $0.5 \%$ SDS, $50 \%$ formamide, $100 \mu \mathrm{g}$ $\mathrm{m} l^{-1}$ sonicated salmon sperm DNA and an RNA probe of antisense CHS, which was prepared from the cDNA clone obtained here using a DIG luminescent detection kit (Boehringer Mannheim). Washes were carried out using $0.2 \times \mathrm{SSC}, 0.1 \% \mathrm{SDS}$ at $65^{\circ} \mathrm{C}$. The membrane was exposed to X-ray film (FUJI-RX).

A cDNA library ( $2 \times 10^{5}$ independent plaques $)$ was constructed from mRNA of strawberry cells. More than 50 clones with positive signals was screened using a carrot CHS probe, and 7 clones were purified. One clone having 1410 bp length was sequenced. Figure 1 shows the complete nucleotide sequence of the cDNA. The clone contained a 1170-bp open reading frame that encoded a 390 -amino acid polypeptide with a molecular weight of 42,488 daltons.

The nucleotide sequence of a partial fragment of CHS cDNA (394 bp) obtained from ripening strawberry fruit [8] has $96.7 \%$ similarity to that of cultured cells (Fig.1). Three amino acids were different because of frameshift (Fig.1). This 
A

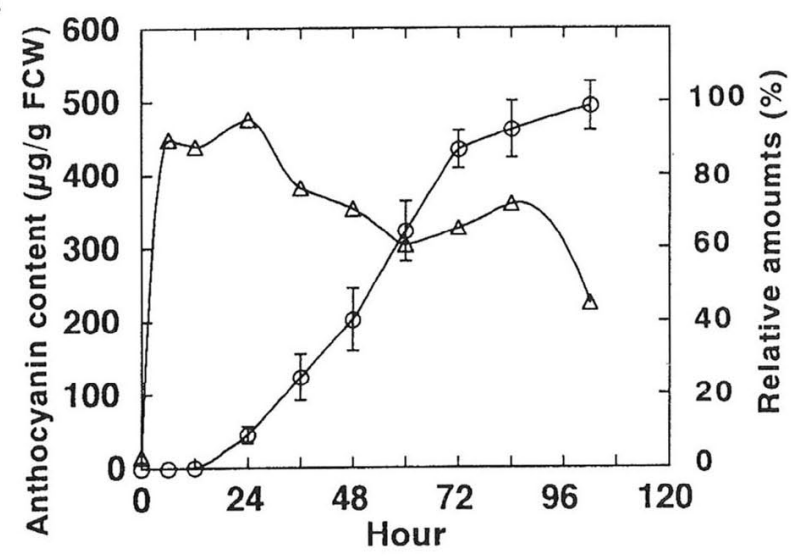

B

CHS 1234456788910

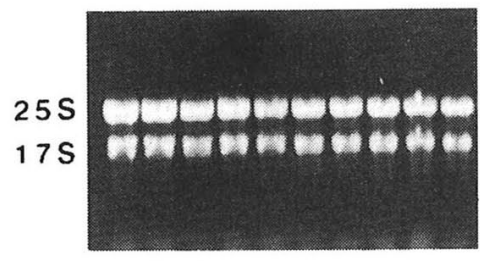

$0 \quad 6122436$

486072

$84102 \mathrm{~h}$

Fig. 2 (A) Changes of anthocyanin content ( $\bigcirc)$ and relative amounts $(\%)$ of $\mathrm{CHS} \operatorname{mRNA}(\triangle)$ under a light condition.

Seven-day-old subcultured cells (2 $g$ of fresh weight) were transferred to fresh LS medium and cultured under darkness for four days, and thereafter cultured under 8,000 lux. Cells were harvested at $0,6,12,24,36,48,60,72,84$ and $102 \mathrm{hr}$ after light illumination (8,000 lux), anthocyanin content was calculated $(\mu \mathrm{g} / \mathrm{g}$ fresh cell weight) and mRNA was extracted.

(B) Northern blot analysis on CHS mRNA accumulation under 8, 000 lux.

Ten $\mu \mathrm{g}$ RNA was loaded onto the gel and hybridization was carried out using a full length cDNA obtained in this work as a probe. Culturing time after light irradiation; lane 1: $0 \mathrm{hr}$, lane 2: $6 \mathrm{hr}$, lane 3: $12 \mathrm{hr}$, lane 4: $24 \mathrm{hr}$, lane 5: $36 \mathrm{hr}$, lane 6: 48 $\mathrm{hr}$, lane 7: $60 \mathrm{hr}$, lane 8: $72 \mathrm{hr}$, lane 9: $84 \mathrm{hr}$, lane 10: $102 \mathrm{hr}$. 25S and 17S ribosomal RNAs were used as internal controls of RNA contents (bottom).

difference is thought to be caused by the difference of cultivar between Pajaro and Shikinari.

To examine the relationship between anthocyanin synthesis and the CHS gene expression of cells cultured under light, the anthocyanin content was monitored (Fig. 2-A) and northern hybridization was performed (Fig. 2-B).

When the cells were cultured under the condition of darkness, no anthocyanin accumulated. However, anthocyanin synthesis began in the cells $12 \mathrm{hr}$ after transfer from darkness to a light condition of 8,000 lux (Fig. 2-A). Strong expression of the CHS gene was first observed in the cultured cells after $6 \mathrm{hr}$ cultivation under 8,000 lux, and the high level expression was kept throughout the cultivation period until $96 \mathrm{hr}$ (Fig. 2-B). The similar result was reported by Takeda et al. [11]. They investigated changes in CHS mRNA using carrot suspension cells induced by light. They suggested that anthocyanin synthesis was induced by the activation of the CHS gene and that CHS mRNA remained at a high level during anthocyanin synthesis under light illumination. However, the expression of the CHS gene was gradually stagnated after $24 \mathrm{hr}$ (Fig. 2-A). This result was consistent with the anthocyanin content obtained after $72 \mathrm{hr}$, because it showed an equilibrium state.

\section{References}

[1] Reimold, U., Kroger, M., Kreuzaler, F., Hahlbrock, K., 1983. EMBO J., 2: 1801-1805.

[2] Chappell, J., Hahlbrock, K., 1984. Nature, 311: 76-78.

[3 ] Cramer, C. L., Ryder, T. B., Bell, J. N., Lamb, C. J., 1985. Science, 227: 1240-1243.

[4] Wrolstad, R. E., Putnam, T. B., 1969. J. Food Sci., 34: 154.

[5 ] Given, N. K., Venis, M. A., Grierson, D., 1988. Planta, 174: 402-406.

[6] Mori, T., Sakurai, M., Shigeta, J., Yoshida, K., Kondo, T., 1993. J. Food Sci., 58: 788-792.

[7] Mori, T., Sakurai, M., Seki, M., Furusaki, S., 1994. J. Sci. Food Agric., 65: 271-276.

[ 8 ] Wilkinson, J. Q., Lanahan, M. B., Conner, T. W., Klee, H. J., 1995. Plant Mol. Biol., 27: 1097-1108.

[9] Linsmaier, E. M., Skoog, F., 1965. Physiol. Plant., 18: $100-127$.

[10] Ozeki, Y., Davies, E., Takeda, J., 1993. Plant Cell Physiol., 34: 1029-1037.

[11] Takeda, J., Abe, S., Hirose, Y., Ozeki, Y., 1993. Physiol. Plant., 89: 4-10. 